Advanced Technologies \& Materials

Original orticle

\title{
Porosity distribution in metal injection molded parts
}

\author{
Samir Butković, Emir Šarić, Muhamed Mehmedović
}

University of Tuzla, Forculty of Mechanical Engineering, Bosnia and Herzegovina

\begin{abstract}
Metal injection molding technology is commonly used in production of small and very complex parts. Residual porosity is unavoidable characteristic of $P / M$ parts, affecting their final properties. During injection molding phase powder-binder separation can occur, causing green density variation through cross section of the part. This behaviour is particularly pronounced as complexity of the parts increases. As a consequence, zones with different density and residual porosity can be seen after sintering. In this regard, porosity and hardness distribution of the sintered ring-shaped part is analysed and presented in the paper.
\end{abstract}

Key words: Metal injection molding, sintering, porosity distribution;

\section{INTRODUCTION}

Typical and unavoidable characteristic of parts produced by powder metallurgy technologies is residual porosity. Size, shape and distribution of residual porosity are factors that have very high influence on final mechanical and physical properties of the PM parts. Source of the residual porosity may be related to compaction (molding) process, as well as sintering process. Ability of green part to shrink evenly during sintering depends on its geometry, condition after compaction (anisotropic oriented microstructure), green density uniformity, etc. [1,2].

During die compaction process, powder is pressed in die in order to form shape of the part. Pressure from the punch is distributed through the compact which causes increasing of contact surfaces between powder particles and their cold welding, Fig. 1.

Pressure variation, as well as density, through the cross section of the compact is dependent on friction between particles and friction between powder particles and die wall.

This behaviour of powder during compaction leads to formation of zones with different percent of residual porosity, Fig1. Empty spaces can also be formed under bridges formed by irregular shaped powders, while spherical powder easily flow and fill empty spaces in green part [3]. Metal injection molding technology usually uses spherical powder, mixed with specified binder, which is injected in to die cavity. During injection molding phase, mixture of binder and powder (feedstock) is heated to temperature where binder becomes liquid.

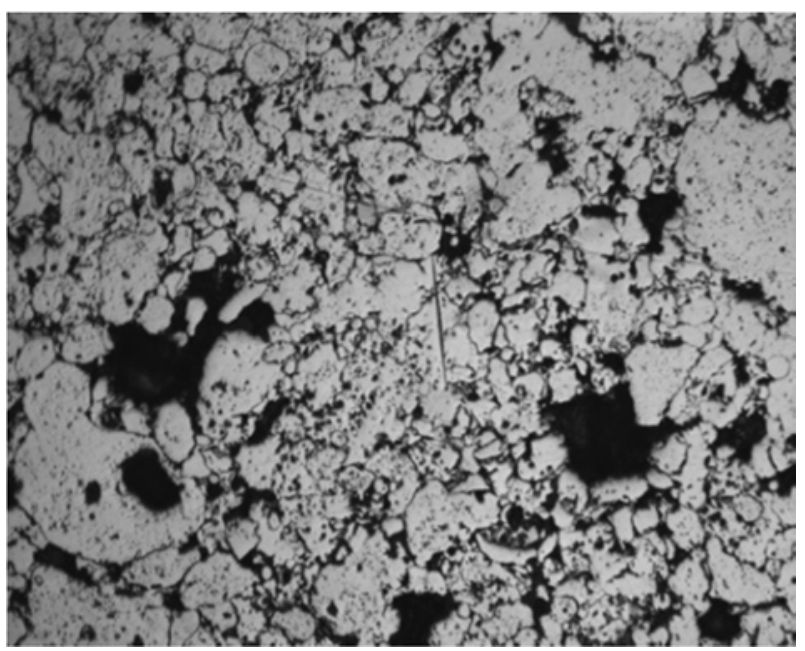

Fig.1 Polished sample of as-compacted copper alloy powder

Feedstock is then injected into die cavity, while binder carries the powder to the farthest distances. Using this

*Corresponding author's.e-mail: samir.butkovic@untz.ba

Published by the University of Novi Sad, Faculty of Technical Sciences, Novi Sad, Serbia.

This is an open access article distributed under the CC BY-NC-ND 4.0 terms and conditions 
principle, it is possible to obtain very complex shapes with superior properties compared to other PM technologies.

However, uneven porosity distribution in MIM parts is usually related to separation of binder and metal powder, causing binder rich and powder rich zones in green parts $[4,5,6]$. Namely, movement of powder particles from high shear rate zones to low shear rate region can result in powder accumulation in the middle of the flow [6].

Flow obstacles, sudden directional changes of feedstock and gravity can cause accumulation of powder in some zones $[4,6]$. This behaviour can be improved through feedstock preparation phase or using favorable molding conditions, but complete avoiding of binder-powder separation can't be achieved.

In this regard, porosity and hardness distribution of the sintered ring-shaped part is analyzed and presented in the paper.

\section{EXPERIMENTAL WORK}

Analysis of porosity distribution was performed on small, very complex ring-shaped part. Injection molding was done in Arburg 320C molding machine. Feedstock was prepared from spherical heat resistant stainless steel powder mixed with poliacetal based binder „Catamold $310 N^{\prime \prime}$.

Injection molding was done using mold temperature of $125^{\circ} \mathrm{C}$, holding pressure of 850 bar and injection speed of $6 \mathrm{~cm}^{3} / \mathrm{s}$. After injection molding, most of the binder was removed by catalytic debinding in nitric acid and nitrogen atmosphere. Rest of the binder was removed during first stage of sintering. In this stage initial joining of the particles takes on the function of the residual binder and keeps the shape of the part. Sintering was done in Elnik furnace, at temperature of $1310^{\circ} \mathrm{C}$.

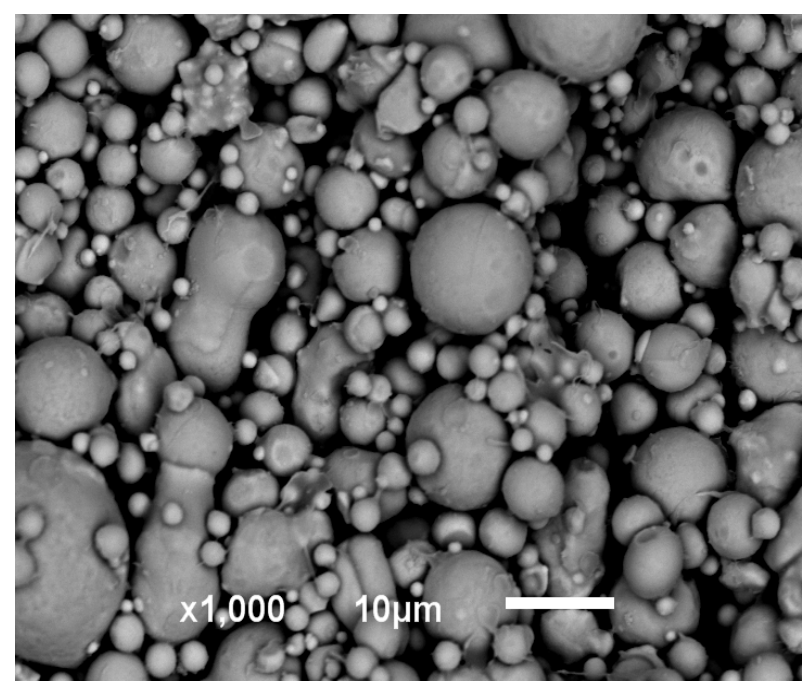

Fig.2 SEM image of metal powder (Catamold 310N) X40CrNiSi 25-20

Nitrogen atmosphere was used during sintering and cooling of the parts. Spherical powder, with well distributed fine particles between coarse particles, can be observed in the Fig. 2. During debinding stage, gas nitrogen enriched with evaporated nitric acid circulates around the parts, causing degradation of binder from the surface to the part core.

After removing the most of the binder, empty space and residual binder remain in the parts. Increasing of the parts temperature, at the beginning of the sintering process, initiates diffusion processes which are responsible for neck formation and degradation of residual binder. After $3 \mathrm{~h}$ at the sintering temperature, final geometry is obtained, and the final mechanical and physical properties of parts were achieved, Fig. 3. Then, part was cut, grinded and polished.

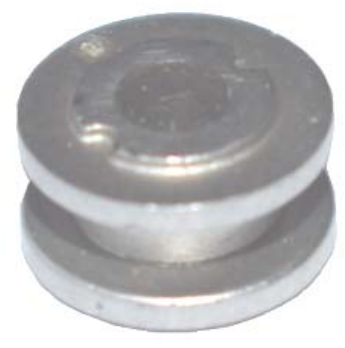

Fig.3 Part after sintering

Polishing and etching was done few times in order to reveal pores on the analyzed surface of the part. After preparing the surface, metallographic examination was performed. Mould filling progression and distribution of the porosity on polished part was presented in the Fig.4 and Fig. 5, respectively.

\section{RESULTS AND DISCUSSION}

During injection phase of the MIM process, liquid binder carries spherical powder particles from cylinder trough runner system up to the die cavity. Passing through the runner system, mixture of powder and binder changes flow direction encountering various obstacles. Binder rich zones can be recognised in sintered parts as porosity rich zones. Also, these zones have higher capacity for shrinking, compared to powder rich zones, which can result in anisotropic shrinking and defects after injection molding and sintering [7]. For the part presented in the Fig.4, where four cavities tool was used, feedstock changes its direction four times at angle of $90^{\circ}$, until reaches the gate. Process of filling the die cavity starts at gate position with injection speed of $6 \mathrm{~cm}^{3} / \mathrm{s}$. High shear rate gradients occur at the gate and separation of powderbinder can occur [6].

Gate zone (1) in this case is specific because feedstock impacts opposite wall at very high speed, Fig.4. This zone of the part can be considered as zone with high potential for binder separation, where accumulation of powder takes place. Thus, lower porosity can be observed in zone 1, Fig.5. From this position feedstock is depleted with powder and the rest of the cavity is filled with reduced powder/binder ratio compared to origin mixture. 

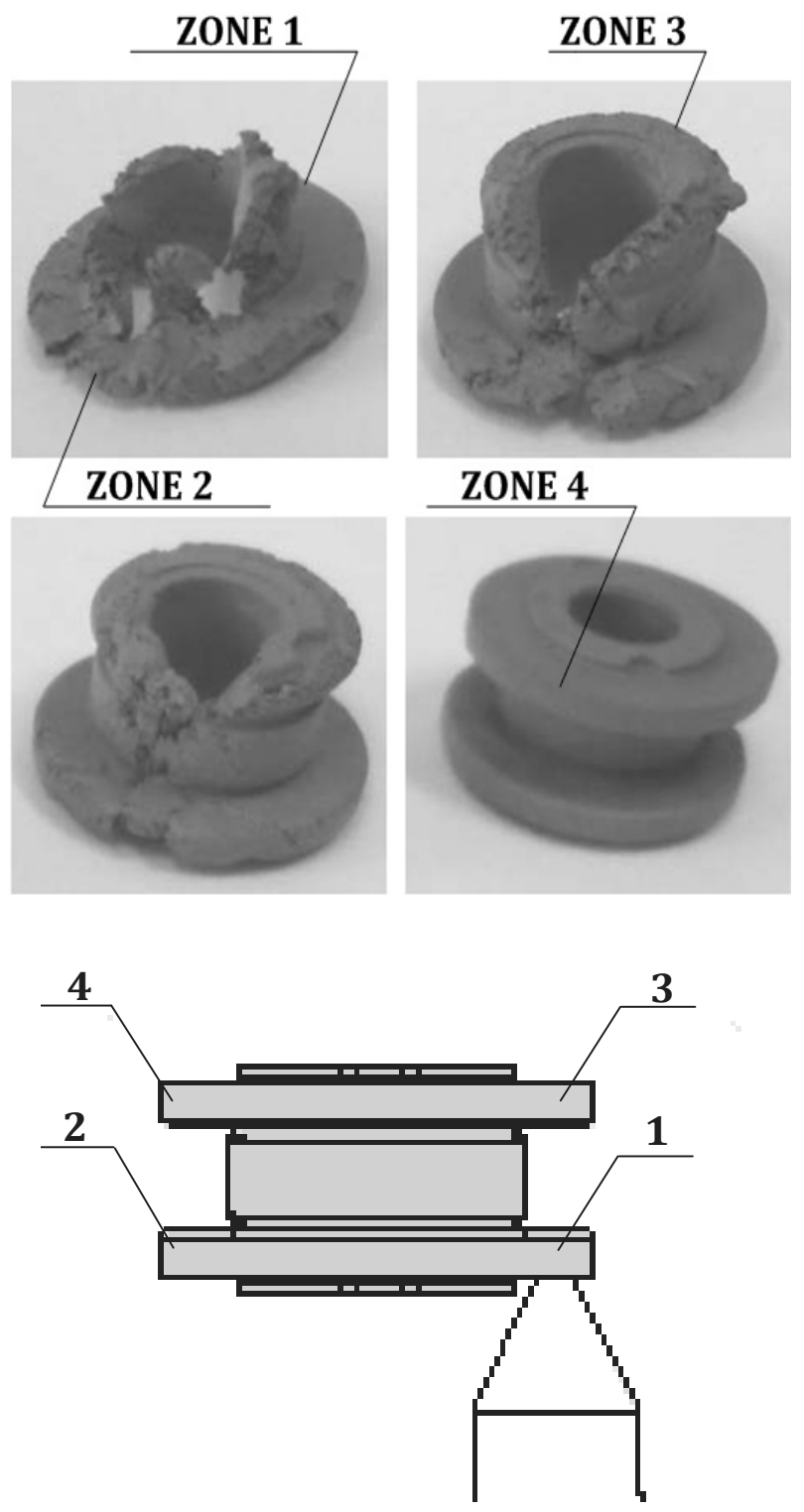

Fig. 4 Mould filling progression and part zones [7]

After zone 1, feedstock goes to zone 2 and then to the zone 3, Fig. 4. These two zones showed similar percent of residual porosity, Fig.5. Zone 4 is the last filled, with significantly changed feedstock composition compared to zone 1. Feedstock with the lowest powder/binder ratio arrives at position 4 , where excessive porosity can be observed.

Experimental results showed that thin zones of the part and zones at the greater distances from the gate, where powder percent in feedstock is reduced, have higher percent of porosity.

Variation of porosity also affected hardness distribution through the part. Hardness analysis was performed on zones with higher densities (gate position, thicker zones) and zone with the lowest density (zone 4). Average hardness at gate position is $207,3 \mathrm{HV}$, while average hardness at the zone 4 , where the highest porosity was observed, is 188,7 HV, Fig. 6.

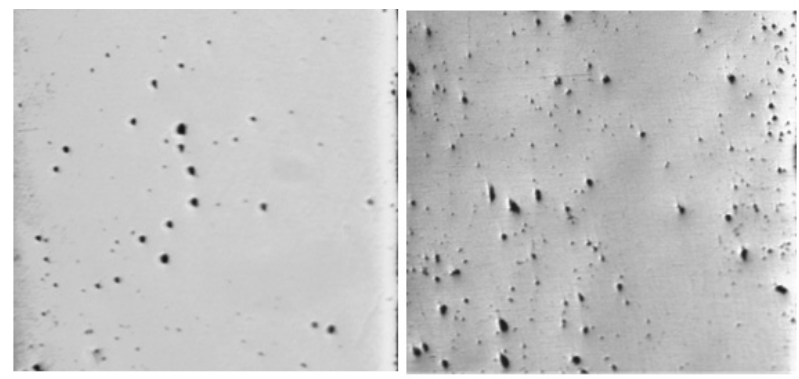

ZONE 1

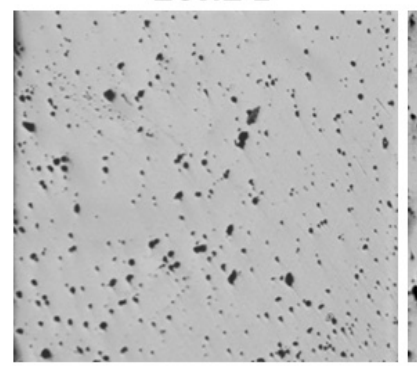

ZONE 3

\section{ZONE 2}

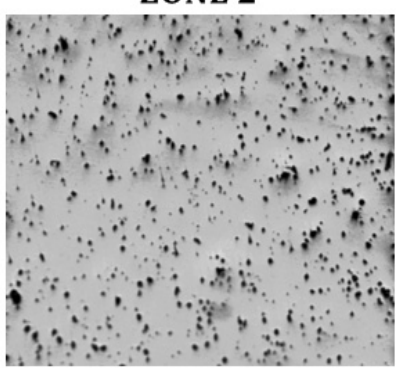

ZONE 4
Fig. 5 Sintered and polished sample of ring-shaped Catamold 310N steel part, revealing residual porosity for different zones, 200X

The highest hardness was observed at position of gate and zones with higher thickness. Other analysed positions of the part showed significantly lower hardness. Also, results showed that lower porosity caused smaller hardness variation compared to more porous zones.

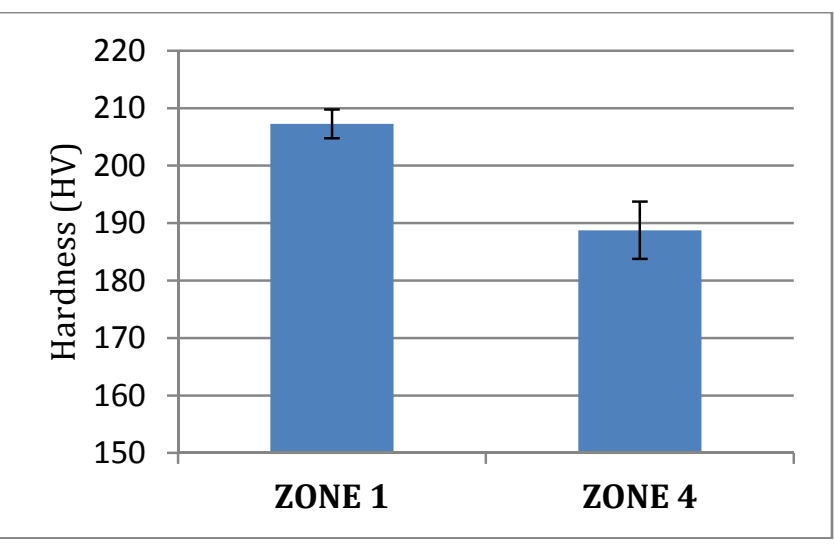

Fig. 6 Hardness of sintered part

\section{CONCLUSIONS}

Metallographic examination of ring-shaped part, produced by metal injection molding, showed inhomogeneous properties through the cross section. Residual porosity varied from very low value in powder accumulation zones to very high percent in binder rich zones. Separation of powder and binder during molding is the main reason for density variation in the green part. Gate zone is powder accumulated zone with very low porosity, while the thin walls and remote regions are high porosity zones. Variations of porosity caused significant variations in hardness through the cross section of the part. Hardness varied from $188,7 \mathrm{HV}$ in very porous zones to $229 \mathrm{HV}$ in 
porosity-free zones. This behaviour leads to density variation in the final part and variation in mechanical properties after sintering, even though the same sintering conditions were applied. Different shrinking capabilities of the different zones of the same part during sintering may cause uneven shrinking and part deformation. Also, it is expected that separation of MIM feedstock intensifies as part complexity increases.

\section{REFERENCES}

[1]. Zavaliangos Antonios, Missiaen Jean-Michel, Bouvard Didier. (2006). Anisotropy in Shrinkage During Sintering, Science of Sintering, DOI: 10.2298/SOS0601013Z, 13-25.

[2]. Nicolò Corsentino. (2016). Development of a design procedure accounting for the anisotropy of the dimensional change in Powder Metallurgy parts, Doctoral Thesis, University of Trento, Department of Industrial Engineering.

[3]. John W. Carson, Brian H. Pittenger, Jenike \& Johanson, Inc.. (1998) ASM Handbook, Volume 7: Powder Metal Technologies and Applications Bulk Properties of Powders. ASM International

[4]. Emir Šaric, Muhamed Mehmedovic, Samir Butković. (2016). Effect of injection parameters and cavity position on MIM green part mass, Journal of Trends in the Development of
Machinery and Associated Technology, Vol. 20, No. 1, ISSN 2303-4009 (online), 29-32.

[5]. Fang Wei, He Xinbo, Zhang Ruijie, Yang Shidi, Qu Xuanhui. (2014). The effects of filling patterns on the powder-binder separation in powder injection molding, Powder Technology, Volume 256, 367376.

[6]. Marco Thornagel, Simulating flow can help avoid mould mistakes, From: https://www.materialstoday.com /molding-andpressing/features/simulating-flow-can-help-avoidmould-mistakes, 5 October 2010. accessed on: April 02, 2021.

[7]. Šarić, E., Mehmedović, M., Butković, S., (2015). Metal powder injection molding technology - Phase injection and molds (in Bosnian), University of Tuzla.

\section{NOTE}

This paper is based on the paper presented at 15th International Conference on Accomplishments in Mechanical and Industrial Engineering - DEMI 2021, organized by University of Banja Luka, Faculty of Mechanical Engineering, in Banja Luka, Bosnia \& Herzegovina, May 2021. 